COMUNICAÇÃO CIENTÍFICA

\title{
ENRAIZAMENTO DE ESTACAS DE PINHEIRA (Annona squamosa L.) COM ÁCIDO INDOLBUTÍRICO ${ }^{1}$
}

\author{
TATIANA DE LIMA SALVADOR ${ }^{1}$, TACIANA DE LIMA SALVADOR ${ }^{2}$, \\ EURICO EDUARDO PINTO DE LEMOS ${ }^{3}$, PÉRICLES GABRIEL BARROS ${ }^{4}$, \\ ROUSSEAU DA SILVA CAMPOS
}

RESUMO - A pinheira (Annona squamosa L.) apresenta boas perspectivas econômicas para a fruticultura brasileira, e sua propagação tem sido realizada comumente de forma seminífera; todavia, a propagação vegetativa de plantas selecionadas é o método mais indicado para a formação de pomares uniformes e produtivos. A estaquia apresenta vantagens que incluem a facilidade da técnica e seu baixo custo. A aplicação de auxinas sintéticas, como o ácido indolbutírico (AIB) na base da estaca, garante o suprimento exógeno, auxiliando no processo do enraizamento. Este trabalho objetivou estabelecer a concentração e o método de aplicação do AIB, visando ao estímulo ao enraizamento em estacas de pinheira, e estudar os tecidos que as formaram. Independentemente da concentração, a aplicação do AIB via pó foi significativamente mais eficiente para a formação das raízes do que na forma líquida. Os estudos anatômicos revelam que as raízes surgem de forma indireta, a partir do tecido caloso, formado na base das estacas.

Termos de indexação: Auxina, propagação vegetativa, AIB, fruteira tropical.

\section{ROOTING CUTTINGS OF SUGAR APPLE (Annona squamosa L.) WITH INDOLEBUTYRIC ACID}

\begin{abstract}
Sugar apple (Annona squamosa L.) presents good economic perspectives for the Brazilian fruit market and its propagation has been held commonly by seeds, however, the vegetative propagation of selected plants is the most appropriate method for the formation of uniform and productive orchards. The use of stem cuttings has advantages including ease of technique and its low cost. The application of synthetic auxins like indolebutyric acid (IBA) at the base of the cuttings ensures its exogenous supply, assisting in the process of rooting. The importance of knowledge of the internal structure of the stem cuttings can reveal the success or failure of rooting that, in some cases, occurs by the presence of anatomical barriers to the emergence of root primordia. This work aimed to establish the best concentration and the method of application of IBA, aimed at stimulate rooting in sugar apple cuttings, and to identify the tissues that they emerged. Independent of the concentration, application of the IBA via powder was significantly more efficient for the formation of roots than liquid form. Anatomical studies reveal that the roots arise indirectly from the callus tissue formed at the base of cuttings.
\end{abstract}

Index temrs : Auxin, IBA, vegetative propagation, tropical fruit.

\footnotetext{
'(Trabalho 068-13) - Recebido em: 21-02-2013. Aceito para publicação em: 31-07-2013. V Congresso Internacional \& Encontro Brasileiro sobre Annonaceae: do gene à exportação (19 a 23 de Agosto).

${ }^{2}$ Engenheira Agrônoma, Mestranda em Agronomia - Universidade Federal de Alagoas, Brasil. E-mail: tatinhalima.11@hotmail.com ${ }^{3}$ Professor Associado, Dr., Universidade Federal de Alagoas, Brasil. E-mail: eepl@uol.com

4,5Engenheiro Agrônomo, pesquisador SEAGRI-DIPAP, Alagoas, Brasil. E-mails: periclesgabriel@ig.com.br, rousseaucampos@ hotmail.com
} 
A pinheira (Annona squamosa L.) é fruteira tropical de grande importância econômica, e sua produção irrigada vem crescendo a cada ano em várias regiões do Brasil, com destaque para as regiões semiáridas do Nordeste e Sudeste, gerando emprego e renda para as populações de vários municípios (DIAS et al., 2004).

Devido sua precocidade, a pinheira tem sido propagada geralmente por sementes, não sendo assim possível, entretanto, garantir integralmente as características genéticas da planta-matriz. A propagação por estacas tem sido um método utilizado em várias espécies lenhosas pela sua facilidade e rapidez na formação das mudas. Na produção de mudas por estacas, o ácido indolbutírico (AIB) tem sido a auxina sintética mais utilizada por ser altamente efetiva no estímulo ao enraizamento, em função de sua menor mobilidade, menor fotossensibilidade e maior estabilidade química na planta (HARTMANN et al., 2011).

De acordo com Fachinello et al. (2005), considerando o método de estaquia, para que ocorra o enraizamento, devem-se observar diversos fatores, dentre os quais as, condições fisiológicas da plantamatriz, tipo de estaca, época do ano, potencial genético de enraizamento, sanidade, balanço hormonal, umidade e temperatura. Ainda segundo os mesmos autores, a formação das raízes adventícias também está ligada à translocação de substâncias, em especial as auxinas, sendo que, quando aplicadas e os fatores citados anteriormente forem satisfeitos, haverá a formação das raízes adventícias.

A formação de raízes adventícias pode ocorrer de forma direta ou indireta. A formação direta compreende o início das raízes a partir das proximidades do sistema vascular, típico de espécies de fácil enraizamento. Na formação indireta, os primórdios radiculares iniciam-se nos tecidos dos calos, evoluem para uma conexão com o sistema vascular, característica típica de espécies de difícil enraizamento (FERRIANI et al., 2008).

Este trabalho objetivou testar diferentes métodos de aplicação e concentrações do ácido indolbutírico, no estímulo ao enraizamento em estacas de Annona squamosa e identificar os tecidos que deram origem aos primórdios radiculares.

O experimento foi conduzido em delineamento inteiramente casualizado, em esquema fatorial de dois fatores, sendo: dois métodos de aplicação (líquido e pó) e cinco concentrações do AIB ( $0 ; 1.000 ; 2.000$; 3.000 e $4.000 \mathrm{mg} \mathrm{kg}^{-1}$ )], totalizando dez tratamentos com três repetições e três estacas por parcela. Para a aplicação da auxina na forma de pó, diluiu-se o sal de AIB em talco inerte, nas concentrações de $0 ; 1.000$;
2.000; 3.000 e $4.000 \mathrm{mg} \mathrm{kg}^{-1}$. Para a aplicação da auxina na forma líquida, primeiramente, dissolveuse o sal do AIB em $20 \mathrm{~mL}$ de álcool etílico $96^{\circ} \mathrm{GL}$ e diluiu-se em água destilada para obter-se as mesmas concentrações descritas acima.

Estacas semilenhosas foram obtidas de brotações vigorosas de pinheiras com quatro anos de idade, no município de Palmeira dos Índios-AL, padronizadas em $12 \mathrm{~cm}$ de comprimento e mantidas com quatro folhas cortadas transversalmente. $\mathrm{O}$ tempo de imersão das bases das estacas nas soluções de AIB foi de cinco minutos. Na forma de pó, a base da estaca foi umedecida com água e tratada com AIB. Após o tratamento, as estacas foram colocadas em tubetes plásticos com volume de $150 \mathrm{~cm}^{3}$, contendo o substrato comercial Bioplant $\AA$ e mantidas em casa de vegetação com nebulização intermitente e umidade relativa do ar acima de $80 \%$. Após 60 dias, avaliouse a porcentagem de estacas com calos e enraizadas. Os dados experimentais foram submetidos à análise de variância, e as médias obtidas foram comparadas pelo teste de Tukey, a 5\% de probabilidade.

Adicionalmente a este experimento, foi realizado um estudo com 50 estacas submetidas às mesmas condições do tratamento-controle para se identificar a iniciação das raízes adventícias nas estacas. Aos 15; 20; 25; 30 e 35 dias após o plantio, foram retiradas dez estacas para estudo histológico, que foi feito através da retirada de amostras dos últimos $2 \mathrm{~cm}$ das bases das estacas. O preparo de lâminas histológicas foi feito de acordo com a metodologia proposta por Ribeiro et al. (2011): na desidratação, foi utilizado álcool em concentrações crescentes $(70 \%-100 \%)$, com o objetivo de extrair a água dos tecidos vegetais. No processo de diafanização, foi utilizado o xilol, retirando as impurezas do material e deixando os cortes translúcidos, prontos para receber a parafina. Após o processo de desidratação e diafanização, os materiais foram transferidos para o borel contendo parafina líquida pura e levados para estufa com temperatura de $\pm 65^{\circ} \mathrm{C}$, por 24 horas, repetindo o processo com a troca da parafina por mais 24 horas. A inclusão foi feita através da passagem dos materiais que estavam na estufa para uma forma (Barra de Leucart), onde receberam parafina líquida, e foram transferidos para refrigeração abaixo de $0^{\circ} \mathrm{C}$, para serem resfriados mais rapidamente, solidificando a parafina e dando origem aos chamados "blocos de parafina". Cortes com espessuras de $7 \mu \mathrm{m}(0,007 \mathrm{~mm})$ foram obtidos em micrótomo de rotação do tipo Leica RM 2125RT com navalha descartável. Posteriormente, os cortes foram distendidos em água previamente aquecida a $\pm 38^{\circ} \mathrm{C}$ em banho-maria e pescados sobre lâmina 
histológica. As lâminas com os cortes fixados foram transferidas para a placa aquecedora (Vertex DBII), para dissolução da pequena parafina restante nas placas e extensão do material. Após o processo de extensão, o material vegetal foi preparado para receber a coloração em Azul de Astra e Safranina. Feita a coloração, as lamínulas foram fixadas nas lâminas com resina sintética. Este processo impede que haja a hidratação do material cortado pela umidade do ambiente, permitindo que estas permaneçam estáveis por tempo indefinido. Após a fixação das lamínulas, as lâminas ficaram prontas para a visualização no microscópio óptico.

$\mathrm{O}$ enraizamento de estacas de pinheira tem sido descrito como difícil por Marinho e Lemos (1996), mesmo com a utilização do AIB, não ultrapassando $26 \%$ de estacas enraizadas. Os resultados desta pesquisa apresentaram valores superiores a $70 \%$, sem diferenças significativas entre os tratamentos testados (Figura 1). Valores superiores a $70 \%$ de enraizamento são considerados comercialmente satisfatórios por Mindêllo Neto et al. (2006).

A formação de calos nas bases das estacas de pinheira não foi influenciada pelo método de aplicação do AIB (pó ou líquido), porém, para a formação de raízes, o método influenciou significativamente na porcentagem de estacas enraizadas (Figura 2). A aplicação do AIB na forma de pó mostrou-se significativamente superior ao método por via líquida, apresentando $86 \%$ (pó) e $66 \%$ (líquido), independentemente da concentração do AIB utilizada (Figura 2). O uso do pó como veículo para a aplicação do AIB tem-se mostrado também efetiva em estacas de quaresmeira [Tibouchina sellowiana (Cham.) Cogn.] na concentração de 3.000 mg kg-1 (BORTOLINI et al., 2008) e de goiabeira (Psidium guajava L.) na concentração de $2.000 \mathrm{mg}$ $\mathrm{kg}^{-1}$ (YAMAMOTO et al., 2010).

A maior eficiência da via sólida na aplicação do AIB para as estacas de pinheira pode estar relacionada a uma exposição mais longa e moderada do AIB sobre os tecidos-alvo, uma vez que os cristais da auxina são insolúveis em água e, em contato com a base ferida da estaca, vão sendo dissolvidos somente à medida que as células reagem com o produto (SANTOS et al., 2011). Entretanto, a exposição das estacas ao AIB, durante 5 minutos, por via líquida, nas concentrações utilizadas, possivelmente pode ter provocado algum tipo de toxidez aos tecidos (FACHINELLO et al., 2005).

Os cortes histológicos longitudinais realizados nas bases das estacas de pinheira revelaram que os primórdios radiciais surgem sempre dos tecidos parenquimatosos do calo, e estes iniciam-se na região do câmbio vascular. A partir dos 15 dias, os primórdios puderam ser observados, e as raízes, propriamente ditas, puderam ser visíveis externamente a partir dos 25 dias.

Raízes formadas com origem em calos nas estacas também foram descritas por vários autores em ensaios realizados em Coffea arabica L.(HAMANN, 1998; ONO et al., 1992), em Leucadendron discolor E. Phillips \& Hutch. (PERÉZ-FRANCÉS et al., 2001) e em Piptocarpha angustifolia Dusén ex Malme (FERRIANI et al., 2008), todas consideradas espécies de difícil enraizamento. Em todos estes casos, os primórdios radiculares surgiram a partir dos calos nas bases, apresentando evidências de uma conexão vascular posterior à sua formação.

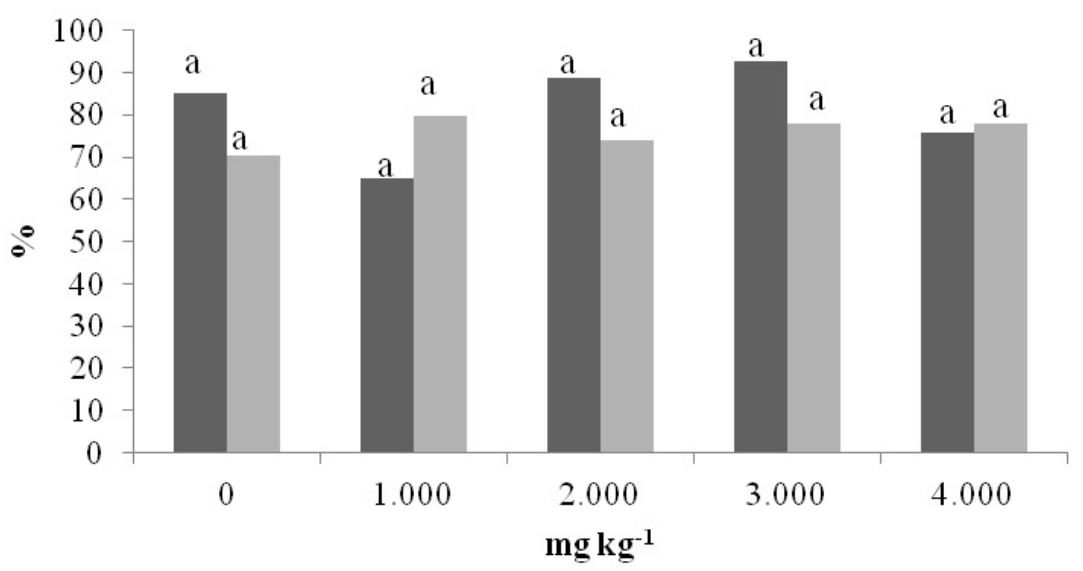

FIGURA 1 - Porcentagem de estacas com calos e com raízes em Annona squamosa L. tratadas com AIB, nas concentrações de $0 ; 1.000 ; 2.000 ; 3.000$ e $4.000 \mathrm{mg} \mathrm{kg}^{-1}$. (Maceió-AL, 2010). 


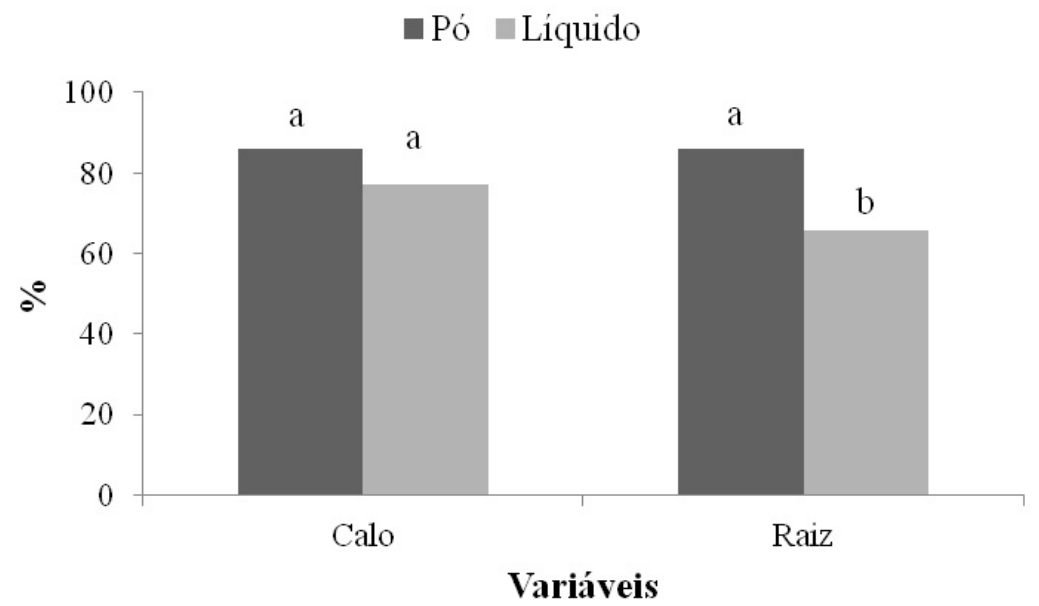

FIGURA 2- Porcentagem de estacas com calos e com raízes em Annona squamosa L. tratadas com aplicação em pó e líquido de AIB. (Maceió-AL, 2010).

\section{REFERÊNCIAS}

BORTOLINI, M. F.; ZUFFELLATO-RIBAS, C.; KOEHLER, H. S.; CARPANEZZI, A. A.; DESCHAMPS, C.; OLIVEIRA, M. C.; BONA, C.; LISCHKA, J.; MAYER, S. Tibouchina sellowiana (Cham.) Cogn.: enraizamento, anatomia e análises bioquímicas nas quatro estações do ano. Ciência Florestal, Santa Maria, v. 18, n. 2, p. 159-171, abr.jun. 2008.

DIAS, N. O.; SOUZA, I. V. B.; SILVA, J. C. G.; SILVA, K. S.; BOMFIM, M. P.; ALVES, J. F. T.; REBOUÇAS, T. N. H.; VIANA, A. E. S.; SÃO JOSÉ, A. R. Desempenho vegetativo e reprodutivo da pinheira (Annona squamosa L.) em função de diferentes comprimentos de ramos podados. Revista Brasileira de Fruticultura, Jaboticabal, v. 26, n. 3, p. 389-391, dezembro 2004.

FACHINELLO, J. C.; HOFFMANN, A.; NACHTIGAL, J. C.; KERSTEN, E. Propagação vegetativa por estaquia. In: FACHINELLO, J. C.; HOFFMANN, A.; NACHTIGAL, J. C. Propagação de plantas frutíferas. Brasília: Embrapa Informação Tecnológica, 2005. 221p.

FERRIANI, A. P.; MAYER, J. L. S.; ZUFFELLATORIBAS, K. C.; BONA, C.; KOEHLER, H. S.; DESCHAMPS, C.; CARPANEZZI, A. A.; OLIVEIRA, M. C. Estaquia e anatomia de Vassourãobranco. Scientia Agraria, Curitiba, v.9, n.2, p.159166, 2008.
HAMANN, A. Adventitious root formation in cuttings of loblolly pine (Pinus taeda L.): developmental sequence and effects of maturation. Trees Physiology, Vancouver, v.12, n.3, 175-180. 1998.

HARTMANN, H. T.; KESTER, D. E.; DAVIES JR., F. T.; GENEVE, R. L. (2011) Plant propagation: principles and practices. $8^{\text {th }}$ ed. New Jersey: PrenticeHall, 2011. 915p.

MARINHO, A. G.; LEMOS, E. E. P. Efeito da aplicação de auxinas no enraizamento de estacas adultas de pinha (Annona squamosa L.). In: CONGRESSO BRASILEIRO DE INICIAÇÃO CIENTÍFICA EM CIÊNCIAS AGRÁRIAS, 10., 1996. Fortaleza. Anais... Fortaleza: UFC, 1996. p.134.

MINDÊLLO NETO, U. R.; TELLES, C. A.; BIASI, L.A. Enraizamento de estacas lenhosas de ameixeiras tratadas com ácido indolbutírico. Ciência Rural, Santa Maria, v.36, n.2, p.448-452, 2006.

RIBEIRO, A. L. T.; COSTA, A. C.; DENADAI, C. R.; FONSECA, E. M. A.; PEGHIM, F.; PENTINO, J. A.; RODRIGUES, L. A.; ANTONINI, P. M.; CARVAlHO, P. M.; MAZZI, V. C. Preparo de lâminas histológicas. Barretos: Centro Universitário da Fundação Educacional de Barretos. Disponível em: <www.cdcc.sc.usp.br/ciencia/artigos/art.../ Aprendendo_lâminas.doc $>$. Acesso em: 10 maio. 2011. 
SANTOS, M. Q. C.; LEMOS, E. E. P.; SALVADOR, T. L.; REZENDE, L. P.; LIMA SALVADOR, T.; SILVA, J. W. ; BARROS, P. G.; CAMPOS, R. S. Rooting soft cuttings of soursop (Annona muricata) 'Giant of Alagoas' ISSN 0567-7572. Acta Horticulturae, Leuven, v. 923, p. 241-246, 2011.

ONO, E. O.; RODRIGUES, J. D.; PINHO, S. Z. Interações entre auxinas e ácido bórico, no enraizamento de estacas caulinares de Coffea arabica L. CV. Mundo Novo. Scientia Agricola, Piracicaba, v. 49, p. 23-27, 1992.
PERÉZ-FRANCÉS, J. F.; MELIÁN-CAPOTE, M. N.; MARTIN-PERÉZ, R.; RODRIGUEZ-PERÉZ, J. A. An anatomical study of adventitious root development in wounded cuttings of Leucadendron discolor and Leucadendron "Safari Sunset" (Proteaceae). Acta Horticulturae, Leuven, p. 191-194. 2001.

YAMAMOTO, L. Y.; BORGES, R. S.; SORACE, M.; RACHID, B. F.; RUAS, J. M. F.; SATO, O.; ASSIS, A. M.; ROBERTO, S. R. Enraizamento de estacas de Psidium guajava L. 'Século XXI' tratadas com ácido indolbutírico veiculado em talco e álcool. Ciência Rural, Santa Maria, v.40, n.5, p.1037-1042, 2010. 